\title{
Double Blind Study of Bisoprolol and Atenolol in Hypertension and Myocardial Infarction in Human Subjects
}

\author{
Dr Zaheda Bano M. D, \\ Pharmacology,Guntur Medical College,Guntur,India
}

\begin{abstract}
:
Objectives: To compare the efficacy of bisoprolol and atenolol in hypertension, myocardial infarction and effect on lipid levels.

Materials and methods:

18 patients whose blood pressure was above 95mm $\mathrm{Hg}$ (Diastolic) or higher were recruited from hypertension clinic. They were given either $A$ or $B$ alternatively. B.P.were recorded both supine and standing position at 30 minutes interval after 2 weeks again B.P. was recorded. In the same way 14 patients were recruited for myocardial infarction. Before giving the drug E,C.G. and blood for lipid profile were taken. After 4weeks again the same procedure were repeated. Results were tabulated and comparison and significance were tested by unpaired students ' $t$ ' test and their ' $p$ ' value was calculated. Results were also shown graphically.

Results

Bisoprolol had consistently significant effect than atenolol in hypertension,myocardial infarction and in reducing lipid profile levels.

Summary and conclusion:

In this double blind study, bisoprolol had consistently greater antihypertensive effect than atenolol $(p<0.05>0.02)$ in supine and in standing ( $p<0.01>0.001)$.In Myocardial infarction ,bisoprolol worked more quickly than atenolol.Bisoprolol statistically significant in reducing blood triglycerides and LDL levels. So the efficacy of Bisoprolol is more both in hypertension and in myocardial infarction.
\end{abstract}

Key words: Atenolol. bisoprolol, hypertension, Myocardial infarction

\section{Introduction}

Hypertension and myocardial infarction are probably the most important public health problems today. The role of sympathetic nervous system in the etiology of hypertension has been well established. So alpha and beta adrenergic antagonists were tries since 1958 . The cardio selective beta 1 blockers continue to be the $1^{\text {st }}$ choice ${ }^{(1)}$ The newer beta 1 blocker bisoprolol had got much more efficacy over atenolol.

Many studies had done previously ${ }^{(2,3)}$ So, a double blind study was done on human subjects at Government General Hospital Guntur.

\section{Aims And Objectives}

To compare the efficacy of bisoprolol $5 \mathrm{mg}$ and atenolol $50 \mathrm{mg}$ in hypertension $(3,14)$ and myocardial infarction ${ }^{(15-17)}$ and also for reducing the lipid profile levels in the body ${ }^{(1819)}$

\subsection{Bisoprolol ${ }^{20-25}$}

\section{Drugs}

It is a derivative of phenoxyamino proponol.It is more lipophilic than atenolol so it had got more absorption rate .Plasma protein binding is 30 . Plasma t1/2 10-12 hrs. It is a well tolerated drug.

\subsection{Atenolol}

It is strongly hydrophilic and poorly lipophilic Plasma protein binding is 5 . Plasma $1 / 268$ hrs. Biological half life 20hrs.It is also well tolerated

\section{Materials And Methods}

It was a double blind study performed at hypertension and cardiology of Government General Hospital, Guntur After getting drug from companies the medicines were prepared by the clinical pharmacologist as in two 
separate capsules and the code was given as drug A and drug B .Only after completion of the study it was decoded and that particular drug was informed to the investigator Both male and female patients are included .Pediatric patients with history $f$ congestive heart failure renal failure liver disease pulmonary disease hematological diseases and pregnant ladies are excluded 18 patients were recruited for hypertension for 2 weeks and given either drug A or drug $\mathrm{b}$ alternatively. BP was recorded in supine and standing positions at $30 \mathrm{~min}$ interval at the same time of the day.14 patients were recruited for myocardial infarction for 4 weeks and given either drug A or drug B alternatively

Before \& after ECG and blood for lipid profile were taken. All results were tabulated and comparison and significance were tested by unpaired student $t$ test and their $\mathrm{P}$ values were calculated .Results were shown graphically also

\section{Results}

Bisoprolol had a consistently greater antihypertensive effect than Atenolol. Compared with Atenolol, Bisoprolol reduced mean supine blood pressure $-22.56 \mathrm{~mm} \mathrm{Hg}$ (diastolic and $-47 \mathrm{~mm} \mathrm{Hg}$ (Systolic). The corresponding reductions seen with Atenolol were $-12.11 \mathrm{~mm} \mathrm{Hg}$ and $-33.33 \mathrm{~mm} \mathrm{Hg}$ respectively. The difference in antihypertensive effect between Atenolol and Bisoprolol were statistically very significant for diastolic blood pressure $(\mathrm{p}<0.05>0.22)$ in supine position. The difference between the two was not of much significance for systolic blood pressure $(\mathrm{p}=0.10)$.

Similarly Bisoprolol achieved significantly greater reductions in standing blood pressure reducing the diastolic blood pressure by $-20.33 \mathrm{~mm} \mathrm{Hg}$ and systolic blood pressure $-45.44 \mathrm{~mm} \mathrm{Hg}$ corresponding figures for Atenolol were $-8.56 \mathrm{~mm} \mathrm{Hg}$ and $-30.33 \mathrm{~mm} \mathrm{Hg}$ respectively. The difference in antihypertensive effect between Atenolol and Bisoprolol was statistically very significant for diastolic $(\mathrm{p}<0.01>0.001)$. The difference between the two was not of much significance for systolic blood pressure $(p>0.55)$.

\subsection{In Myocardial Infarction}

All patients except two responded well to both Bisoprolol and Atenolol. But Bisoprolol worked more quickly than Atenolol. It reduced the symptoms like chest pain from $2 \mathrm{hrs}$ to $24 \mathrm{hrs}$. Atenolol reduced it from $6 \mathrm{hrs}$ to $48 \mathrm{hrs}$. Both drugs reduced the mean resting heart rate, but the difference is not statistically significant ( $p>0.10)$.

\subsection{E.C.G. Findings}

Both the drugs reduced the QTC values except in two patients. But the difference between these two drugs were not statistically significant $(\mathrm{p}>0.10)$.

\subsection{Lipid Profile Values:}

Bisoprolol decreased the serum triglycerides, serum cholesterol, LDL and VLDL levels and it increased the cardio protective HDL levels.

On the whole Atenolol increased the Serum triglycerides, serum cholesterol LDL and VLDL levels and it decreased the cardio protective HDL levels.

Bisoprolol significantly decreased the triglyceride level $(\mathrm{p}<0.01)$ as well as LDL levels $(\mathrm{p}<0.05>0.01)$. The difference between the two drugs in other parameters was not statistically significant.

\subsection{Adverse effect in both hypertension and myocardial infarction:}

The side effects noted in patients under Bisoprolol were tingling, numbness, tiredness, easy fatigability, muscular cramps, muscular weakness and head-ache. They were moderate in intensity and did not necessitate withdrawal from the trial.

The other symptoms noted in patients under Atenolol were tingling fatigability, muscular cramps, muscular weakness and head-ache. They were also moderate in intensity and did not necessitate withdrawal from the trial. The side effects disappeared early with Bisoprolol than with Atenolol.

So, Bisoprolol did well both in hypertension and myocardial infarction when compared to Atenolol and also significantly decreased the triglycerides and LDL levels Changes in systolic and Diastolic blood pressure seen during treatment with Bisoprolol and Atenolol in patients with essential hypertension. 
Table 1: Parameters:

\begin{tabular}{|c|c|c|c|c|c|c|c|c|}
\hline \multirow[t]{2}{*}{ Parameters } & \multicolumn{2}{|c|}{ Under Bisoprolol } & \multicolumn{2}{|c|}{ Under Atenolol } & \multirow{2}{*}{$\begin{array}{l}\text { Mean } \\
\text { Diff. }\end{array}$} & \multirow{2}{*}{$\begin{array}{l}\text { Standard } \\
\text { Error }\end{array}$} & \multirow{2}{*}{$\begin{array}{l}\text { 't' } \\
\text { Value }\end{array}$} & \multirow[t]{2}{*}{ 'p' Value } \\
\hline & Mean & S.D. & Mean & S.D. & & & & \\
\hline $\begin{array}{l}\text { Supine Systolic } \\
\text { Blood Pressure }\end{array}$ & -47.00 & +19.69 & -33.33 & +12.85 & 13.67 & 7.84 & 1.74 & $\mathrm{P}=0.10$ (insignificant) \\
\hline $\begin{array}{l}\text { Supine diastolic } \\
\text { blood pressure }\end{array}$ & -22.56 & +11.22 & -12.11 & +7.28 & 10.45 & 4.46 & 2.34 & $\mathrm{P}<0.05>0.02$ (significant) \\
\hline $\begin{array}{l}\text { Standing systolic } \\
\text { blood pressure }\end{array}$ & -45.44 & \pm 20.37 & -30.33 & \pm 10.05 & 15.11 & 7.57 & 2.0 & $\mathrm{p}>0.05$ (insignificant) \\
\hline $\begin{array}{l}\text { Standing Diastolic } \\
\text { blood pressure }\end{array}$ & -20.33 & \pm 10.21 & -8.56 & $+\underline{5.36}$ & 11.77 & 3.84 & 3.07 & $\begin{array}{l}\mathrm{P}<0.01>0.001 \\
\text { significant }\end{array}$ \\
\hline $\begin{array}{l}\text { Heart Rate in } \\
\text { Hypertension } \\
\text { patients }\end{array}$ & -20.00 & +4.42 & -18.00 & \pm 6.86 & 2.00 & 2.72 & 0.74 & $\mathrm{P}>0.10$ (insignificant) \\
\hline Triglycerides & -27.5 & \pm 33.43 & +36.67 & \pm 36.14 & 64.17 & 20.10 & 3.19 & $\begin{array}{ll}\mathrm{P}<0.01>0.001 & \text { Very } \\
\text { Significant } & \end{array}$ \\
\hline Cholesterol & -18.83 & \pm 25.69 & \pm 15.67 & \pm 32.56 & 34.50 & 16.93 & 2.04 & $\mathrm{p}>0.05$ (insignificant) \\
\hline HDL & +6.17 & \pm 4.83 & -3.17 & \pm 3.01 & -9.34 & 2.32 & -4.03 & $\mathrm{p}>0.10$ (insignificant) \\
\hline VLDL & -7.50 & \pm 13.40 & 0 & \pm 10.66 & +7.50 & 6.99 & 1.07 & $\mathrm{p}>0.10$ (insignificant) \\
\hline LDL & -26.67 & +19.90 & -1.17 & +18.87 & +25.50 & 11.06 & 2.31 & $\mathrm{P}<0.05>0.02$ (significant) \\
\hline $\begin{array}{l}\text { Heart rate in } \\
\text { Myocardial } \\
\text { infarction patients }\end{array}$ & -5.00 & +4.73 & -9.33 & \pm 13.76 & 4.33 & 5.94 & 0.73 & $\mathrm{p}>0.10$ (insignificant) \\
\hline P R Interval & +0.003 & \pm 0.019 & & +0.022 & -0.03 & 0.012 & -2.50 & $p>0.10$ (Insignificant) \\
\hline $\begin{array}{lll}\text { Heart Rate in } \\
\text { E.C.G }\end{array}$ & +6.33 & \pm 5.13 & -11.17 & \pm 15.85 & -4.84 & 6.80 & -0.71 & $\mathrm{p}>0.10$ (insignificant) \\
\hline
\end{tabular}

Table 2: Bisoprolol In Myocardial Infarction

\begin{tabular}{|l|l|l|l|l|}
\hline Sl.No. & Age & Amount of Ischemia & Other Associated Disease & Response \\
\hline 1. & 62 & Inf. Apical QMI & Nil & Symptoms reduced after 2 hrs. \\
\hline 2. & 43 & Inf. Wall Ischemia & Nil & Symptoms reduced after 6 hrs. \\
\hline 3. & 50 & $\begin{array}{l}\text { Antero Septal QMIc old apicolateral } \\
\text { non QMI }\end{array}$ & Nil & Symptoms reduced after 12 Hrs. \\
\hline 4. & 60 & Ant Wall ischemia & Nil & Sil \\
\hline 5. & 52 & Ischemia & & $\begin{array}{l}\text { Drug is discontinued due to side } \\
\text { effects (tingling and numbness of } \\
\text { head) }\end{array}$ \\
\hline 6. & 50 & Apical and subeithelial injury & Diabetes+HTN & Symptoms reduced after 12 Hrs. \\
\hline 7 & 50 & Apical and apicolateral ischemia & Nil & Symptoms reduced after 24 hrs. \\
\hline
\end{tabular}

Table 3 .Atenolol I N Myocardial Infarction:

\begin{tabular}{|l|l|l|l|l|}
\hline Sl.No. & Age & Amount of Ischemia & Other Associated Disease & Response \\
\hline 1. & 40 & Ischemia & Nil & Symptoms reduced after 6 hrs. \\
\hline 2. & 70 & Old Inf. QMI with apical non QMI & Nil & Symptoms reduced after 12 hrs. \\
\hline 3. & 28 & Ant wall sub epithelial injury & Nil & Symptoms reduced after 24 Hrs. \\
\hline 4. & 60 & Old antero inf. QMI & Nil & Symptoms reduced after 24 Hrs. \\
\hline 5. & 60 & Occational PVC Old Inf QMI & HTN & Symptoms reduced after 24 Hrs. \\
\hline 6. & 40 & High lateral wall ischemia & Nil & Symptoms reduced after 48 Hrs. \\
\hline 7 & 50 & Inf. QMI & & $\begin{array}{l}\text { Symptoms reduced after 12 Hrs, but 6 } \\
\text { days after therapy he again developed } \\
\text { ischemic changes. So, the drug is } \\
\text { discontinued. }\end{array}$ \\
\hline
\end{tabular}


Graph-1
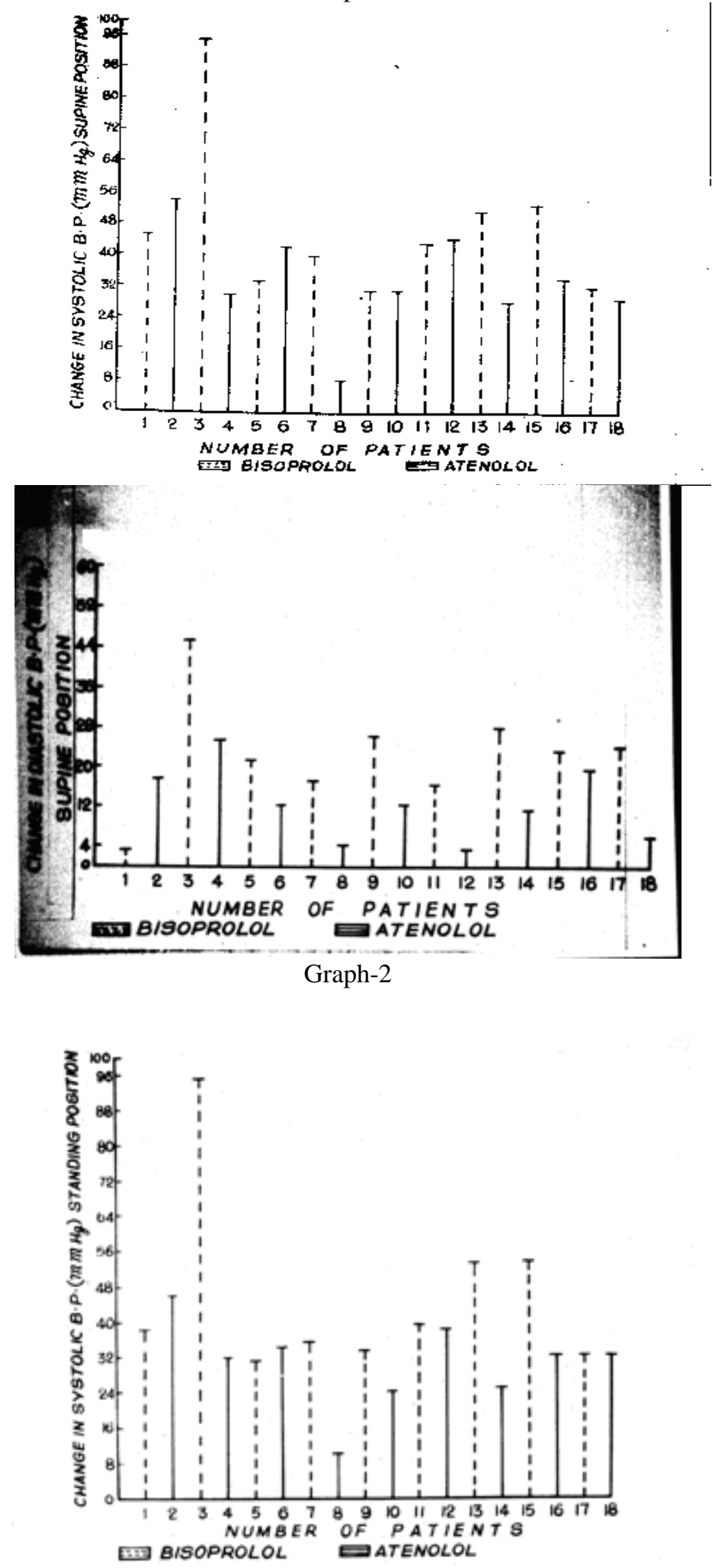

Graph-3 


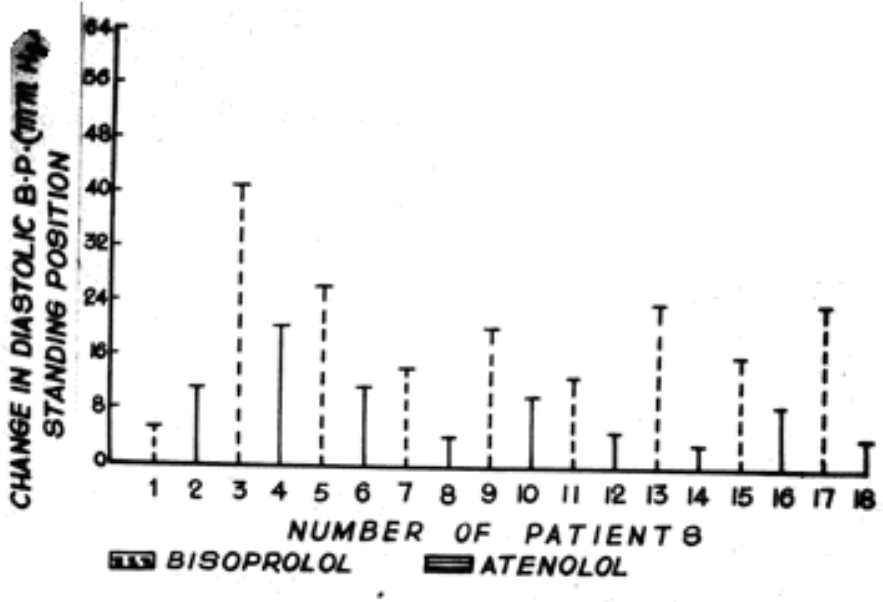

Graph-4

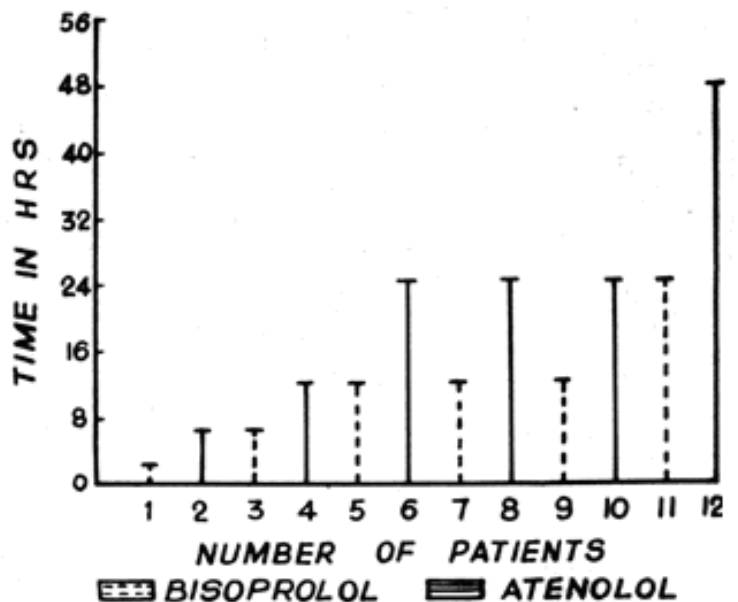

Graph-5

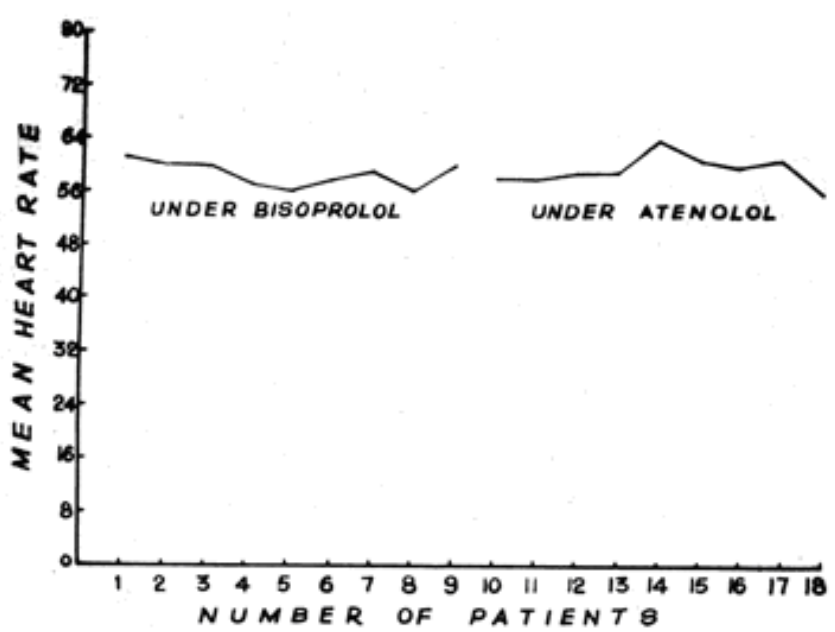

Graph-6 


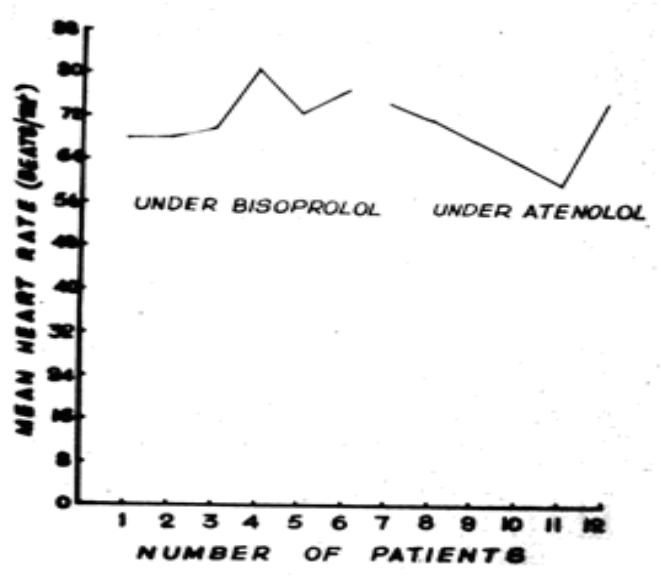

Graph-7

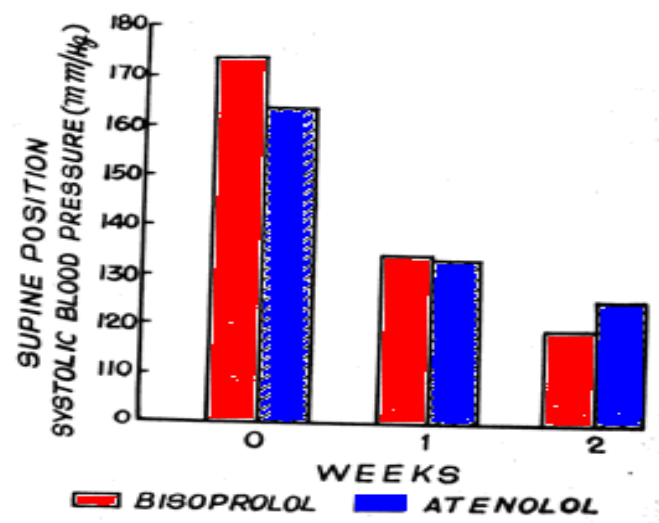

Graph-8.Mean Blood pressure readings before and after treatment with bisoprolol or Atenolol

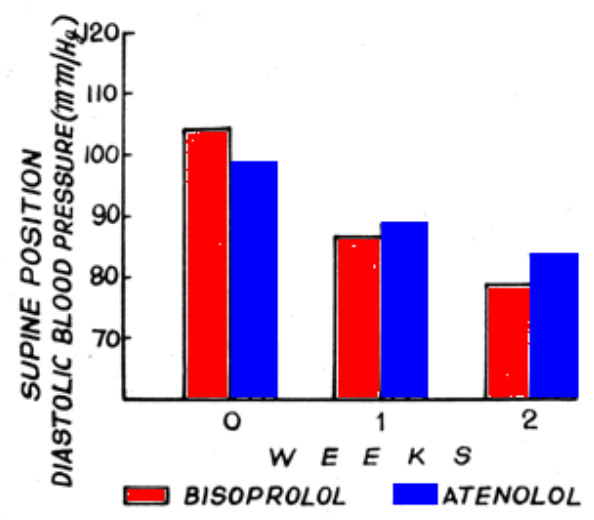

Graph-9.Mean Diastolic blood pressure in supine position before and after treatment with Bisoprolol or Atenolol 


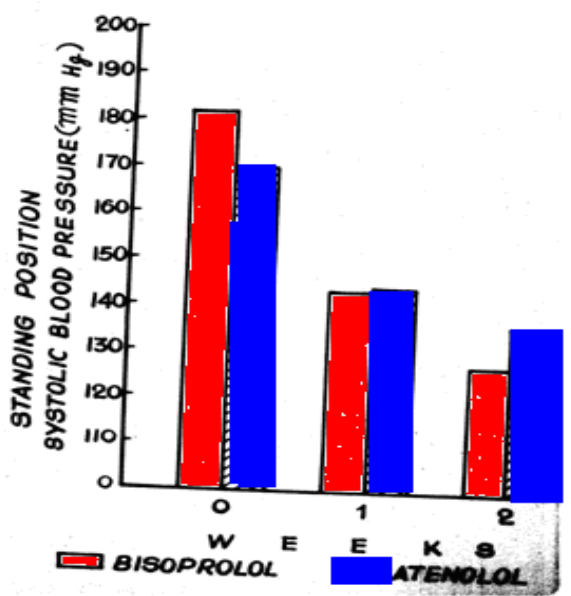

Graph-10.Mean Systolic Blood pressure in Standing Position Before and after treatment with Bisoprolol or Atenolol

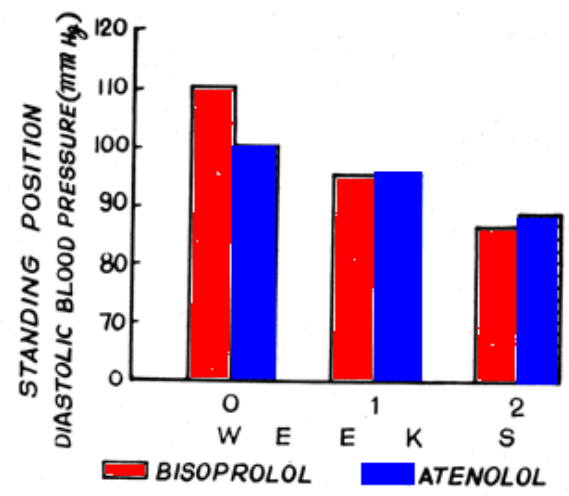

Graph-11

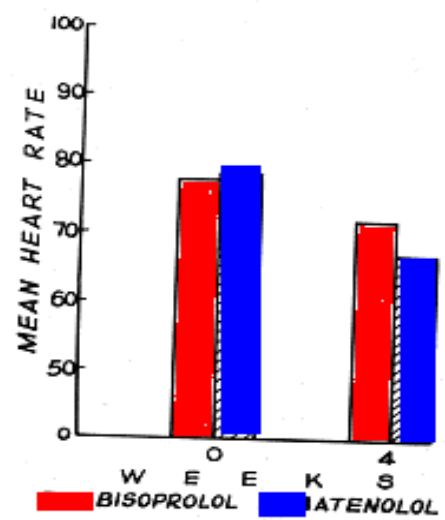

Graph-12 


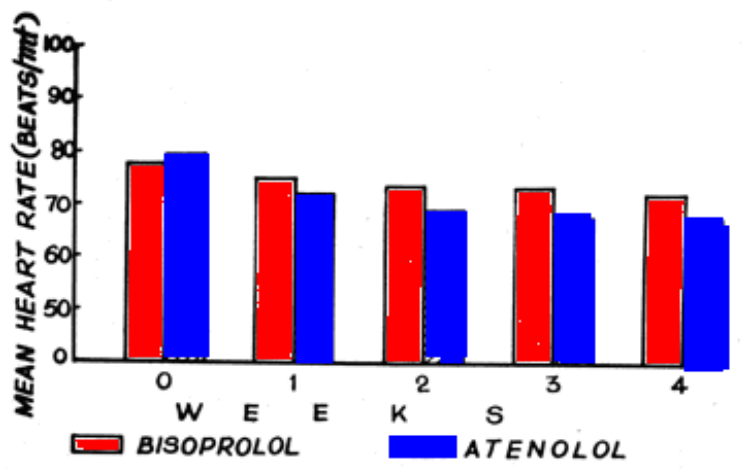

Graph 13

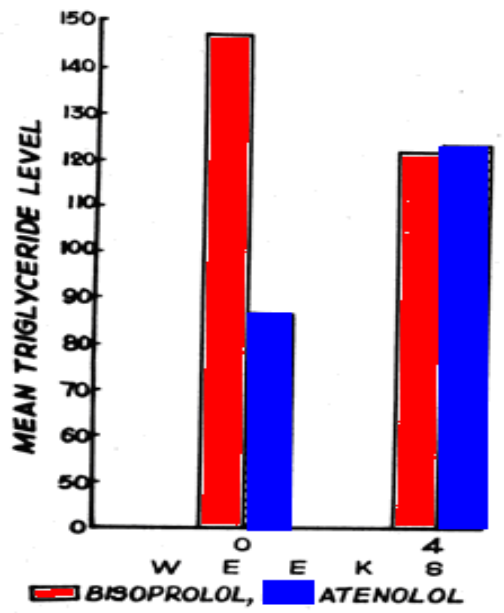

Graph-14

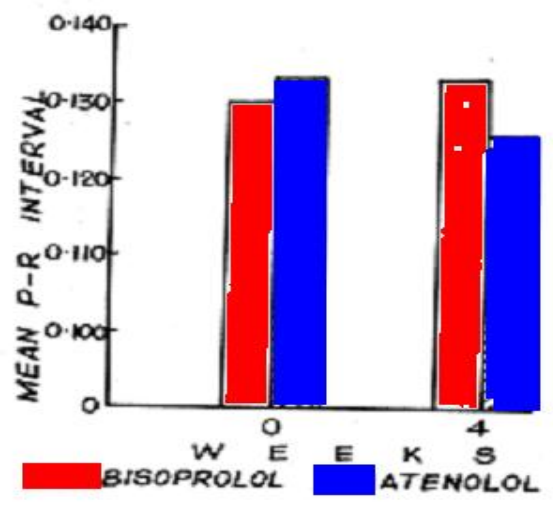

Graph 15 .Mean P.R Interval in myocardial infarction patients seen before and after treatment 


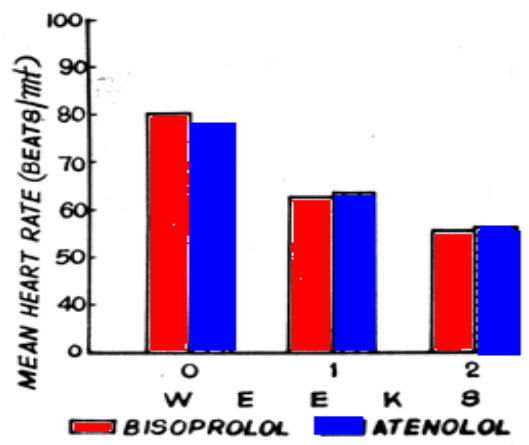

Graph-16 Mean Heart Rates in myocardial infarction patients seen before and after treatment

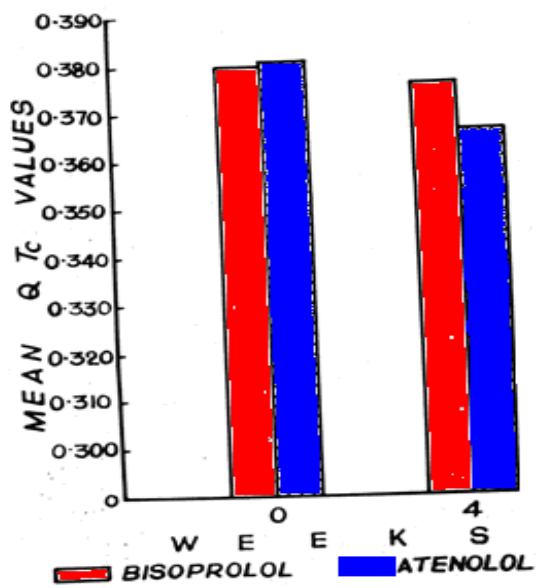

Graph 17 .Mean QTC values in Myocardial Infarction Patients seen before and after treatment

\section{Summary And Conclusion}

The present study is double blind study of bisoprolol and atenolol in myocardial infarction Bisoprolol had a consistently greater antihypertensive effect than Atenolol. The difference in antihypertensive effect between Atenolol and Bisoprolol were statistically very significant for diastolic blood pressure $(\mathrm{p}<0.05>0.02)$. In supine as well as standing position. $(\mathrm{p}<0.01>0.001)$.

In myocardial infarction Bisoprolol worked more quickly than Atenolol. It reduced the symptoms from $2 \mathrm{hrs}$ to $24 \mathrm{hrs}$. Atenolol reduced it from $6 \mathrm{hrs}$ to $48 \mathrm{hrs}$. Both drugs reduced the QTC values but the difference between the two was not statistically significant $(\mathrm{p}<0.10)$.

\subsection{Lipid Profile Values}

Bisoprolol significantly decreased the triglyceride level $(\mathrm{p}<0.01>0.001)$ as well as LDL levels $(\mathrm{p}<0.05>$ 0.02 ). The difference between the two drugs in other parameters was not statistically significant.

\subsection{Adverse Effects:}

Adverse effects were same for the two drugs. But the symptoms disappeared early in the case of bisoprolol than Atenolol.

So, Bisoprolol which is a new highly beta 1 selective beta adrenoceptor antagonist did well both in Hypertension and Myocardial infarction when compared to Atenolol. Because of non availability of drug and its high cost do not 
make use possible to recruit large number of patients. So further studies using large number of patients were necessary to confirm the results.

Each tablet of Bisoprolol cost is Rs 8 If the cost was reduced it is very much beneficial to the people

\section{Acknowledgement}

My sincere thanks to all my professors colleagues helpers patients and e merck india ltd for supplying me the literature and samples

\section{Bibliography}

[1]. Chang P C., Vanveen S, Vander Krogt JA, Vermei J.P., Vanbrummelen P. B1 adren oceptor selectivity of single oral doses of Bisoprolol and Atenolol J Cardiovas Pharmacol 1988 12: 317

[2]. Andrew Whelton M.D., F.A.C.P. F.C.P., Jack M.D and David J. Wagner M.S Sustained Antihypertensive activity of Diltiazerm SR: Double blind placebo controlled study with 24 hrs. Ambulatory blood pressure monitoring, J. of clin Pharm 1992, 32: 808-815

[3]. Brachetti D A double blind comparison of Bisoprolol and captopril for treatment of essential Hypertension in the elderly. Cardiovas. Drugs: ther: 1990, 4: 261.

[4]. Bughler F R Double blind comparison of the cardiosetective $\beta$ blockers, Bisoprolol and ATenolol in Hypertension. The bisoprolol International multicentre study J of Cardiovas Pharmacol 19868 (Supp: 11) 5122.

[5]. Weiner L Fritz G Anti hypertensive effect of Bisoprolol during once daily administration in patients with essential hypertension. A Dose ranging studies with parallel groups. Europ J of clinic Pharm: 1986, 29: $517-$ 21.

[6]. Tattersfield. A.E. Oragg DJ Bacon RJ Assessment of Beta adrenoceptor selectivity of a new beta adrenoceptor antagonist. Bisoprolol, in man. Br. J. of clinic pharm 1984, 18 (3): 343-7.

[7]. Wagner $\mathrm{G}$ Summary of short and long term studies with bisoprolol in coronary heart disease $\mathbf{J}$ of cardiovas. Pharm 1986, 11: s 160-6

[8]. Divitriss O D E Bisprolol in the treatment of Angina pectoris. A double blind comparison with Verapamil Europ Hear J 19878 (suppl:11):439.

[9]. Fogari R Effects of Different beta blockers on Lipid metabolism in chronic therapy of Hypertension, Int $\mathbf{J}$ Clinic Pharm ther 1988,

[10]. Fritz G. Weiner L Effects of Bisoprolol on Blood pressure, Serum Lipids, and HDL - cholesterol in essential Hypertension. Curp K of Clinic Pharm 1987, 32: 77-80.

[11]. Brodde O.E., Bisoprolol (EMD 33512), a highly selective $\beta 1$ adrenoceptor antagonist in vitro and in vivo studies. J of cardiovas. Pharm 19868 (supp 11) : 529.

[12]. Gotz Leopold M D Joachim pabst, Phd, Wold ram Ungethum M.D and Karl-Ulrich buhring, Phd Basic Pharmaco kinetics of Bisoprolol, a new highly $\beta 1$ selective adrenoceptor antagonist J of clinic pharm 1986, 26:616-621.

[13]. Prichard BN Bisoprolol, a new $\beta$ adrenoceptor blocking drug Europeon H J 1987, 8: 121-9.

[14]. Spinar, J Zicha J; Vitovek J. Bisoprolol in the treatment of Hypertension, Vnitrni Lekarster 1993, 39 (9): 86570.

[15]. Tattersfield. A.E. Oragg DJ Bacon RJ Assessment of Beta adrenoceptor selectivity of a new beta adrenoceptor antagonist. Bisoprolol, in man. Br. J. of clinic pharm 1984, 18 (3): 343-7.

[16]. R Ghosh Atenolol, Modern concepts on pharmacology and therapeutics 24th edition. 